\title{
Sociotechnical Design for Mobile Anticoagulant Therapy
}

\author{
Barbara Rita Barricelli · Jose \\ Abdelnour-Nocera • Jennie Wilson . \\ Ken Eason
}

Received: date / Accepted: date

\begin{abstract}
In this paper we present MANTRA (Mobile ANticoagulant TheRApy), a project aimed at studying feasibility and acceptability of the introduction of mobile technology in the management of anticoagulant therapy involving both patients and health practitioners in their design. By the evaluation of the MANTRA Project, we developed a general approach to mHealth in the remote management of chronic diseases by supporting the communication among patients and healthcare practitioners. Patients usually have to make frequent visits to surgeries to meet nurses for the tests, and General Practitioners (GPs) for receiving drug prescriptions. We report on the implementation of the project as a proof of concept in London. A group of patients, General Practitioners, nurses, and healthcare assistants from the National Health Service
\end{abstract}

Barbara Rita Barricelli

Dept. of Computer Science, Università degli Studi di Milano

Via Celoria, 18

20133 Milano, Italy

Tel.: +39-02-50316323

E-mail: barricelli@di.unimi.it

Jose Abdelnour-Nocera

School of Computing and Engineering, University of West London

St Mary's Road

London W5 5RF, UK

E-mail: jose.abdelnour-nocera@uwl.ac.uk

Jennie Wilson

College of Nursing, Midwifery and Healthcare, University of West London

St Mary's Road

London W5 5RF, UK

E-mail: jennie.wilson@uwl.ac.uk

Ken Eason

Design School, Loughborough University

Epinal Way

Loughborough LE11 3TU, UK

E-mail: k.d.eason@lboro.ac.uk 
(NHS) participated in design and evaluation phases. The distinct characteristics of the NHS as one of the world's largest publicly funded health services posed a number of sociotechnical challenges to the design team. We present how we approached and addressed these challenges through MANTRA. Patients and Healthcare practitioners recognized the validity of our proposed design approach not only for supporting the remote therapy practice preserving an efficient and effective communication with the patients, but also as a way for better managing resources in anticoagulant clinics in the context of the NHS. With our research we explored the process that needs to be followed to develop a mobile system that would fit the sociotechnical ecosystem of anticoagulant therapy. Furthermore, we are now able to identify the changes that will be necessary in the ecosystem itself to make an effective use of the mobile system.

Keywords Anticoagulant Therapy · Chronic Diseases · mHealth · Mobile Devices · Sociotechnical Design · Telemedicinee

\section{Introduction}

In this paper we present a general approach to mHealth in the remote management of chronic diseases by supporting the communication among patients and healthcare practitioners. Since the blood coagulation tests are usually performed in surgeries, patients have to make frequent visits to meet nurses for the tests and General Practitioners (GPs) for receiving drug prescriptions. This approach was developed as a core goal of a Leverhulme Trust funded research project, MANTRA (Mobile ANticoagulant TheRApy). The main goal of the MANTRA Project was to study feasibility and acceptability of the introduction of mobile technology in the management of anticoagulant therapy involving both patients and health practitioners in their design [3,2].

In this paper, we report on the implementation of the project as a proof of concept in a London community health centre, also referred to as a surgery in Britain. A group of patients, General Practitioners (medical doctors), nurses, and healthcare assistants from the National Health Service (NHS) participated in the design and evaluation of this device. The distinct characteristics of the NHS as one of the world's largest publicly funded health service posed a number of sociotechnical challenges to the design team. We classified the challenges into four main classes: quality of life, prescription management, treatment schedule, and nutrition. In the paper, we present in detail how we approached and addressed these challenges for our proposed mHealth solution. The results proved a real interest both from the patients and from the surgery's team members. The latter, in particular, recognize the validity of the proposed design approach not only for supporting the remote therapy practice preserving an efficient and effective communication and sharing of records with the patients, but also as a way for better managing resources in anticoagulant clinics. 


\section{Oral Anticoagulation Therapy}

Oral anticoagulant therapy is aimed at preventing the formation of thrombus. People at risk of developing thrombosis have to take anticoagulant treatment once a day in a dosage that varies depending on the results of an INR (International Normalised Ratio) test (see Figure 1) [36]. The two main reasons for coagulation therapy are venous thromboembolism and atrial fibrillation. Venous thromboembolism (VTE) [36] [4] is the presence of coagulated blood, a thrombus, in a major blood vessel. VTE has the potential to cause significant harm by blocking blood flow to major organs and tissues. Many are the possible causes for coagulation diseases - e.g. major general surgery, multiple trauma, hip fracture. Besides, there are also some risk factors, like increasing age, cardiac or respiratory failure, prolonged immobility, presence of central venous lines, estrogens, and a wide variety of inherited and acquired haematological conditions [10]. Most of the times a combination of causes and risk factors are present together in a patient. Atrial Fibrillation (AF) [10] is a cardiovascular disease that is associated with an increased risk of thrombus formation and risk of stroke in patients that are affected by it.

The management of both VTE and AF requires treatment with Warfarin, an oral anticoagulation drug, in a dosage that needs to be adjusted on the basis of the INR test results. The INR test measures how long it takes for the blood to clot, i.e. the prothrombin time. The dose of anticoagulant is adjusted (increased or decreased) in order to maintain the INR result within an appropriate range. The INR is tested every $2-3$ days on the commencement of treatment but once the levels have stabilized the interval between tests will change to between 7 and 20 days. INR tests are usually performed in clinics or laboratories therefore patients have to make frequent visits to have blood taken and for the healthcare practitioner to make the decision about the appropriate anticoagulant dose. The patient must then take exactly the dose prescribed by the healthcare practitioner. This can be difficult for elderly or disabled people and disruptive to their daily lives.

Given the high diversity of situations that may lead to anticoagulant therapy, a very wide spectrum of the population might be affected by this: Children, teenagers, adults and elderly. Each of these groups of people would present different difficulties and needs and their daily life may be influenced in different ways.

One of the most diffused problems for anticoagulant patients in their elderly is that they may miss the daily dose, or they may take the correct dose twice a day. Monitoring this kind of events means to take constant care of the patient night and day and this can be made only if enough time/money resources are present and/or if family members are available to take care or her/him. The assumption of anticoagulant drugs is complex because of the frequently variation of their dosage. In particular, in the UK this task is made even harder because of the combination of some information at the same time: the patient has to remember the dosage to be assumed in a specific day; $\mathrm{S} / \mathrm{he}$ has to choose from 4 kinds of pills which one is the correct one following a 
colour-code but the prescription is expressed in number of mg. as indicated on each pill. These issues may lead to mistakes not only in elderly community, but also for the others. Taking care of a child affected by coagulation diseases is a very time-consuming activity that is very hard to manage for working parents. Concerning teenage patients, giving them the whole responsibility of the management of their cure could be very stressful, and they may not be always very reliable.

Another serious problem related to coagulation diseases cure is given by the fact that INR tests are mostly performed in clinics and laboratories and this means that with a certain frequency the patient has to move to have the test made. Moreover, even if the result of the test is immediately given, the new dosage of the drugs is decided by a healthcare practitioner who has to communicate it to the patient face to face, by email or via fax. If the patient is not provided with email or fax devices, s/he has to stay in the facility until the healthcare practitioner is ready to communicate the new dosage.

Last but not the least important influence on the normal life of a person is nutrition. As reported in [12], foods rich in vitamin K may affect the INR result. Such foods include green leafy vegetables, chick peas, liver, egg yolks, cereals containing wheat bran and oats, mature cheese, blue cheese, avocado and olive oil. For anticoagulant patients is always needed to have access to the list of food they may assume/avoid and this could be a very big problem for children, teenagers and elderly and implicates in general the need of a very strong motivation to take care of themselves.

Our research is based in the United Kingdom, therefore we studied how anticoagulant therapy is put in practice by the NHS system. In the UK, the monitoring of oral anticoagulation therapy is performed in hospital anticoagulation clinics. In a document distributed by [30], the setting up of anticoagulation clinics in primary care is described in terms of issues, quality control, audit, and costs. The report estimates that on the general population of patients with $\mathrm{AF}$, the prevalence for patients on oral anticoagulation therapy is about $1-1.5 \%$. As relevant costs for a clinic, $£ 100$ to $£ 1000$ have to be considered for a Computerized Decision Support Software (CDSS), a system that helps the clinic staff to maintain the quality of anticoagulation control but at the same time allows to reliably increase the average period between INR tests. As ongoing costs, the report lists the main costs per test, that are related to reagents, nursing staff time per hour, administration staff time, accommodation expenses (e.g., heating, light, and cleaning) and all others administrative costs related to the clinic management and its relationship with NHS accreditation.

Obviously, reducing the need for patients to visit personally the clinics, sometimes even may times per month, will reduce the costs of the clinics. On the other hand, a first initial investment has to be taken into account but as discussed in literature (e.g. [23]), such investment would lead in future costs reduction and advantages for the entire health system and patients' quality of life. 


\section{Literature Review}

\subsection{Personal Health Records and mHealth}

Our research is focused on providing to patients and health practitioners systems able at supporting remote, mobile, and asynchronous communication for an effective, safe, and reliable chronic diseases monitoring. Therefore, two are the main fields that we address: personal health records and mHealth (as a specific form of telemedicine based on the use of mobile devices and technology). We observe these two fields from a double perspective, the one of healthcare practitioners and the one of the people affected by chronic diseases.

The scientific literature available today strongly proves how the use of electronic management of health records can be of advantage both for patients and for healthcare practitioners, especially with what concerns a better management of National Health Systems.

A panel at CHI 2013 [8] invited scholars in this field to discuss the impact that technology plays on the relationship and interaction between patients and healthcare practitioners. In particular, the organizers identified three main key points that are worth to be considered: first, the effect that the presence of computers in the exam-rooms or patients rooms have on the conversation between patient and GP. This peculiar aspect of the synchronous co-located interaction between the two actors may often lead to a loss of empathy in the way the GP addresses the patient's needs. Secondly, the problems that affect asynchronous remote interaction, that are mainly related to the risk of patients and providers being afraid of learning new ways of communicating with each other and help them to understand the potentials of this specific setting. Lastly, the changes in the traditional roles of patients and healthcare providers with the introduction of more and more pervasive and ubiquitous technologies. The proactivity of patients in sending their own test results to the GPs may lead to great advantages in a long term perspective, but it is undoubtedly hard to be understood and acknowledged in the short term.

A study focused on understanding the shift that eHealth may cause on the relationship between patient and healthcare provider is published in [11] where the authors report their findings by identifying 5 potential changes (sometimes overlapping): 1) Internet health Websites may become a replacement for faceto-face consultations influencing deeply the patients understanding of their health conditions and putting at risk their own safety and future. However, the same study points out how in literature it is proved that the patients do not usually loose the interest in meeting their GP for examination and consultation; 2) Supplement existing relationships and forms of care, that means making the computer-mediated conversation between patient and GP an actual bi-directional transaction but always allowing the receiver (the GP) driving the communication; 3) Create favorable circumstances for improvements or for strengthening patient participation, by mitigating mechanism, offering a training ground, and implementing a so-called lever effect; 4) Managing the issues that the healthcare practitioners might encounter, like the feeling of 
power loss, the fear of damaging the relationship with the patients during a remote conversation, and to loose control over the sources of information that tend to proliferate very fast due to technological advances; 5) Forcing the patient to become a more capable conversation partner because $\mathrm{s} /$ he needs to provide the doctor with information that the doctor cannot obtain through remote conversation.

mHealth is aimed at providing remote health care by the use of mobile technology and devices. In [19] a systematic review on scientific literature about the management of chronic diseases has been presented and discussed. In particular, the review included the analysis of 107 papers and compared usability, feasibility, and acceptability of mobile tools and platform used. From the results, it emerged that the most commonly used mobile technology $(40.2 \%)$, was still Short Message Service (SMS). Particularly, about the practice of mHealth for anticoagulant therapy management (that is the specific application domain we consider in our research), several studies have been carried out in the past years but none of them ended in actual implementation into practice. In a pilot study in 2006 [17], home telematic devices have been tested with 19 anticoagulant patients over 5 months. The device was used to transmit the INR result to a remote server. The prescription was then given by telephone to the patient, because the device was only able to receive from the server the date of the next test. Due to many severe technical and software problems and failures only 9 home telematic devices were tested. The study proved the feasibility of telemedicine for anticoagulant therapy but with many technical constraints. First of all, this study promoted the use of home devices that are not mobile but need to be connected to landlines and therefore cannot be used while travelling. Another problem was the lack of bidirectional communication via the home telematic device: the healthcare practitioners needed to call the patients of the phone to communicate them the next Warfarin prescription and this procedure was obviously highly error prone. In 2008, Salvador et al. [35] proposed the use of telemedicine for first monitoring and then establishing self-management of anticoagulant therapy. The study involved 54 patients over more than two years and led to conclusions related to the feasibility of telemedicine in anticoagulant therapy and of the introduction of self-management approach, i.e. the use of decision systems to be used by the patients to self-prescribe Warfarin. This research presents the same weakness we highlighted for the previous one: it provides devices that are supposed to be used at home and that are not usable while on a trip. Another interesting research developed in Denmark in 2011 [9], tested a telemedicine system to be used on Personal Computers connected to the Internet. They involved 123 patients and proved, like the other researches presented above, the validity of the adoption of telemedicine for anticoagulant therapy.

By analyzing the existing literature and the outcomes of our research work we can state that there are two main advantages in implementing mHealth solutions for chronic diseases: the first is more related to its social impact and is the increase of patients' awareness in their health condition. The second one is related to a reduction of costs for the National Health Systems. As a significant 


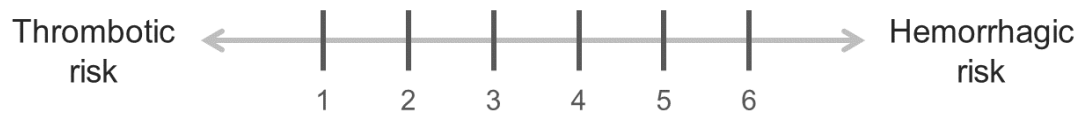

Fig. 1 INR test result shows how long it takes for the blood of the patient to clot. The more the INR value decreases to 1 , the more thrombotic risks are present in the patient. On the contrary, the more the INR value increases to 6 , the more hemorrhagic risks exist.

example, Javitt et al [23] shows that the adoption of mHealth technology for diabetes monitoring can lead to a significant reduction in medical expenditure, estimated in about $\$ 3,000$ per person per year.

\subsection{INR Self-Monitoring and Self-Testing}

INR self-testing devices are freely sold but not currently integrated into the common practice for managing anticoagulant therapy adopted by the clinics. INR self-testing devices allow to easily check the INR value with a finger stick test. Using a lancet, a drop of blood is placed on a test strip that is then inserted in the device.

The devices use three main methods to detect the INR value:

1. Monitoring of change in impedance of the sample when clotting occurs

2. Mechanical endpoint clotting mechanism, monitored optically

3. Mechanical clot detection. With all the devices, the result is available within minutes

INR devices can be used in two ways:

1. Self-testing: the result has to be communicated to a healthcare practitioner who is in charge of deciding the prescription of Warfarin and the date of the next INR check;

2. Self-monitoring: the patients, after a proper and adequate training, selfcheck their INR value and adjust their own Warfarin dosage.

Both these approaches has been widely studied in literature and medical practice.

Many researches published in literature support self-testing and self-monitoring as alternatives to the traditional standard care of patients of all ages [22], [33], [38], and [29].

Two studies are specifically focused on one of the most diffused INR selftesting devices $([21],[7])$. The result of both papers support the fact that selfmanagement of oral anticoagulation therapy is feasible for selected patients and could represent a significant improvement for the management of the patients. Both researches point out that the devices used (CoaguCheck XS) 
appears to be sufficiently accurate and reliable and offers a good consistency and stability as compared with traditional laboratory testing.

Several applications or prototypes have been designed recently to test the feasibility of a mHealth approach to anticoagulation therapy. In 2018, Smaradottir et al. [37] presented and evaluated a mobile application called Warfarine Guide. The application, developed with a user-centred design approach, is a computer-assisted decision-support system aimed at helping patients in their management of anticoagulation therapy on the basis of the INR values. The results of the evaluation show that the application effectively supported self-management of the anticoagulation therapy and that it helped the patients by providing flexibility and decision support. Another prototype has been designed in 2017 by a group of master students [18] with direct involvement of the patients and provided interesting insights on how to design such type of mhealth applications.

Also acceptability of mHealth and self-testing and self-monitoring has been studied. A research of 2008 [39] evaluated an in-hospital education program aimed at teaching INR self-testing to patients. The results of the study show that the patients will continue to use the method without the need for interval instruction. The research reported in [Tompsone438], proved how selfmonitoring of anticoagulation therapy is generally seen as a positive experience by the patients. Especially interesting is the fact that from the interviews to the participants it emerges how they became more conscious of their lifestyle and started reflecting more on their INR level and on their routine without becoming obsessed by it.

\subsection{Open Problems and Challenges}

From a sociotechnical perspective, by the results we obtained from the literature and state of the art review, we can point out that the problem with the majority of the practical case studies in telemedicine and mHealth is that the process of adoption of new technologies is in general very (and too) fast and this mostly leads to the design of tools that do not fit the users need as required and also do not fit into existing relationships between the stakeholders and in the sociotechnical ecosystem in general. There is indeed very high interest in the possibilities of managing chronic conditions at home by using new IT solutions, especially the mobile ones, but the vast majority of trials either fail or do not lead to the technology becoming embedded in normal practice [14].

Said that, what we might need is a pre-trial sociotechnical analysis and system development process in order to design tools that well fit both individual users and the broader setting in which they have to be adopted and put at work.

As described before in this paper, we can classify the main challenges of this research domain into four classes: quality of life, prescription management, 
treatment schedule, and nutrition. Here is a detailed list of the open problem and challenges we obtained as results of our research:

1. Problems in the management of INR test schedule. In particular, the test have to be done in certified facilities that could be far away from patients home and that in any case imply time and resources allocation.

2. The communication of INR test results and of the related dosage is done in different ways that often may not be accessible for children and elderly and very time/resources consuming for pupils and working adults.

3. Difficulties in the management of the daily dosage of oral anticoagulants. Patients have to keep a diary and to remember which dosage they have to take in specific days of the week. Errors in this particular task may be fatal.

4. Nutrition rules should be followed by the patient and very often they represent a limit to their social life. In fact, in case of doubts the patients do not know how to decide if a certain food can be assumed or not and if such food would affect the INR value.

5. The limitations given by coagulation diseases cause problems in social and personal life, and may lead the patients to feel uncomfortable with their daily life and sometimes isolated from the community.

The implementation of feasible, effective and safe mHealth systems can represent a solution for these problems, thanks also to the growing diffusion of smartphones and other mobile devices, and not only among young people. Moreover, providing tools for PHR management may represent a powerful way to empower patients and make them more aware of their health conditions and less dependent from healthcare practitioners frequent personal contact. At the same time the existence of digital PHRs enables the healthcare practitioners to supervise their patients in a more organized way, avoiding charging the National Health Systems, and the whole community, with excessive and unnecessary costs. In the rest of this paper, we present the MANTRA (Mobile ANticoagulant TheRApy) project and discuss its results. With MANTRA, we were able to prove the concept of mHealth adoption in remote oral anticoagulant therapy with an evaluation performed involving both healthcare practitioners and patients.

\section{Methodology}

MANTRA was a research project in mHealth domain aimed at using mobile technology to improve the quality of life of patients with coagulation diseases, to save patients and healthcare workers time and resources, and to facilitate the monitoring of anticoagulant therapy. The project was funded by the Leverhulme Trust and the University of West London, as a proof of concept.

MANTRA proposed to provide the patient with an INR self-testing device and a mobile device (an iPod) to transmit the INR results to the healthcare practitioners. The GP or other healthcare practitioner is then able to review 
the results and transmit back to the patients the correct dose of anticoagulant that they need to take and the date when they need to repeat the INR test. The goal was to provide patients with a monitoring device to be used at home to reduce the frequency of visits at the hospitals or clinics.

The project focused on (a) the feasibility of using this approach in the UK, and on (b) patients and healthcare practitioners acceptability of the use of a mHealth tool.

To investigate the feasibility of implementing MANTRA project in the UK, GPs and other healthcare practitioners of the Argyle Surgery in Ealing, London, were involved. Initially they were interviewed about their current processes for managing patients on anticoagulation therapy, the demographics of their patients receiving anticoagulation therapy, what factors would need to be considered in order to implement the digital solution and their views on its potential value. They have then participated in two further face-to-face meetings to evaluate and test the prototypes designed and developed during the project.

To study patients' acceptability of the system, patients receiving anticoagulant therapy who volunteer to participate were recruited from the Argyle Surgery. They were interviewed about their views and expectations of an interactive system for managing their therapy. In particular, patients' requirements for the user interface were explored and incorporated into the design process. They then have been asked to test the usability of the prototype's user interface. The research was mostly qualitative, with no collection of blood samples or actual performance of INR tests.

With the MANTRA Project, the aim was to explore within the sociotechnical context of the NHS and a GP surgery, the validity of providing patients with self-testing device to be used at home to reduce the frequency of visits at the hospitals or clinics. Using these devices, the patients would be able to send their INR test results to their GP and healthcare practitioners and to receive back their prescriptions details.

Our research background is framed in a sociotechnical design domain, which means evaluating technical and interface design decisions in terms of the social context of use and associated practices and values [6]. This means to not only understanding context and culture separately, but also involving the identification and interpretation of pertinent cultural traits of the actors and the context itself. The understanding and interpretation of the relationship between context, culture and technology is thus well documented. The sociotechnical approach is at the basis of the MANTRA Project, in that the technical solutions we designed and tested consider not only the requirements in terms of data management, data exchange and remote communication, but also the end users' and domain experts' profiles, needs, skills and expectations in order to support information and knowledge exchange and the construction of virtual communities aimed at collaborating for patients' own good [20]. Technical and social were considered as interconnected entities and the co-evolution phenomenon [25] [5] [26] was taken into account when the prototypes were designed and developed. Figure 2 shows the ecosystem of the 
MANTRA Project. The patient plays a central role and has to balance the interactions among two separate but in many ways interconnected spheres of existence: personal life and medical condition. From personal life side, family and friends, caretakers, and coworkers represent the communities in which the patients live and share with their members most of their time. On the other side, their medical condition bounds them to specific activities and gives them constraints on how they can live their life. GPs, nurses, and Healtcare Assistants (HCAs) are the professionals who represent the patients references for managing their condition. Given the variety of the potential patients, it is important to study the context in the widest way possible, especially because the introduction of new technologies in the life of people affected by chronic diseases presents many challenges. It is argued that technology acceptance and adoption depend to a great extent on how end users perceive the technology [27]. It is only logical, therefore, that an understanding of users' cognitive frames helps increasing acceptance and adoption of the technology. Abdelnour-Nocera et al [1] also investigated how the usefulness of an Information System (IS) can be deeply influenced by socio-cultural factors. They found that users and designers may have different perceptions of usefulness and consequently different expectations of a system. Then for a successful ICT design in a context for which the technologies were not initially developed, designers need to assess how the interpretive frames and practices of users in their local context can shape the usefulness of existing or proposed systems. Ehn [15] said once: "One of the oldest and widely accepted principles in the design of computer-based tools for users is the principle know the user." In the same manner, the contextual inquiry, is an approach that consists of finding out about the end users' context and culture with their participation. It uses a mixture of ethnography and other field research approaches providing designers with "(...) grounded and detailed knowledge of user work as a basis for their design." [13]. The advantage with this approach is that users sometimes reveal important issues and concerns that researchers may find worth exploring and sometimes might not be elicited. Also, the focus should encompass the whole design project (global team interests) [24], rather than just focusing on a particular stage. Contextual inquiries as an approach are applied in many forms using a variety of mixed methods. In addition to the most common methods used (survey questionnaires, interviews, focus groups), there are also other User Centred Design (UCD)-oriented methodologies in use in this approach that generate more details about the users' mental models, cognitive frame, initial and general perception of technologies envisaged. However, for the purpose of this project, a more traditional approach was adopted using unstructured interviews and questionnaires.

The general methodology of design research followed in the project is the one described in Figure 3.

The outcome of the first phase was the definition the problem in context that we built also through the literature review on telemedicine and on anticoagulant therapy management that we presented earlier in this paper and through the performance of some informal interviews to healthcare profession- 


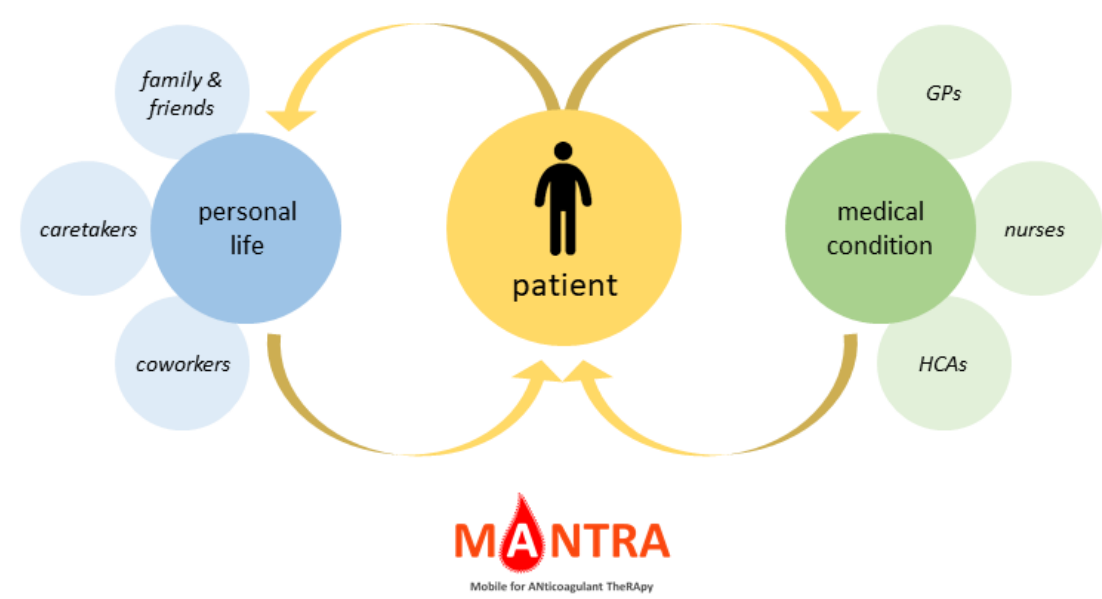

Fig. 2 The sociotechnical ecosystem of MANTRA.

als to better understand how to operate in various scenarios. We then defined future sociotechnical system scenarios and defined a set of personas [34][28] that we used for examine technical options, i.e. the state of the art of existing mobile applications for self-monitoring of INR tests (designed for patients living in urban context and not supporting the communication with doctors) [3]. We then created paper prototypes of the two applications and evaluated them with the doctors to validate the scenario and user requirements. During the last phase we implemented two high-fidelity prototypes able to satisfy the requirements and needs identified during the previous two phases.

It is important to point out that the MANTRA project was mainly about the creation of a sociotechnical system and not just about the delivering of a new mobile technology. Therefore, the aims of this research are more wide than just prototyping, development and evaluation phases.

\subsection{Ethics}

We asked and obtained for Ethics approval from the College of Nursing, Midwifery and Healthcare Research Scrutiny \& Ethics Sub-committee of the University of West London and then we obtained the NRES Ethics approval following a Proportionate Review process. The specific kind of process, a simplified one if compared with other Ethics approval processes of NHS is due to the fact that the MANTRA Project did not consider the collection of blood sample or the use of the self-testing devices. The evaluation of the Project was mainly focused on the sociotechnical design of the idea as a proof of concept and involved the patients and health practitioners only for testing the scenario, interfaces and the idea at the base of the Project. Unfortunately, even if the Proportionate Review process is by definition supposed to be simplified, 


\section{Problem definition}

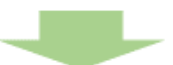

Future sociotechnical system scenarios

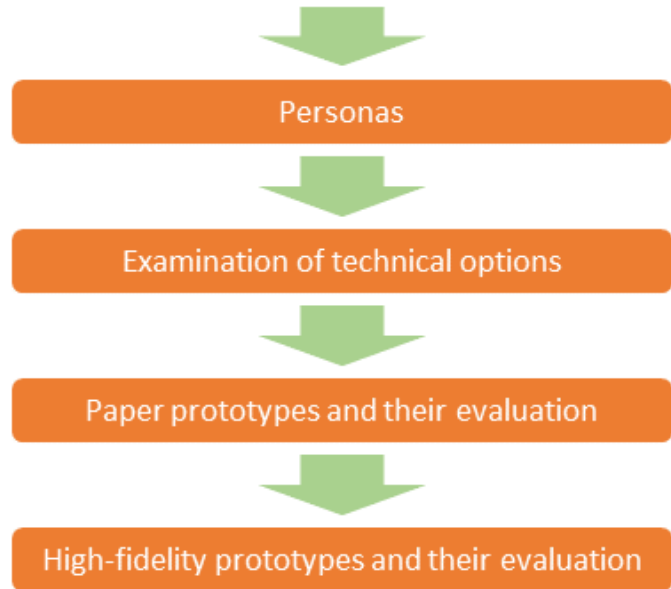

Fig. 3 The adopted research methodology.

it was very time expensive and this affected severely the already limited time resources for the Project, that lasted one year.

\section{Results}

\subsection{Future Sociotechnical System Scenario}

The scenario of use of the MANTRA applications was designed after the analysis of the results of the literature review and interviews performed to the Argyle Surgery healthcare practitioners about their patients and their clinical routine.

It sees the patient being provided with a INR self-testing device and a mobile devices and application. Using these devices, the patient is able to send her/his INR test results to her/his healthcare practitioner and to receive back her/his prescriptions details. In this way, the patient will not have to visit the GP every time the test is scheduled and will be able to travel and conduct a freer life. Moreover, the patient can consult her/his clinical history with the PHR functionality and to access a list of foods that help her/him in deciding what to eat and to make sure Vitamin $K$ is low enough to not influence the INR results. 


\subsection{Personas}

On the basis of the interviews and on the study of literature review, we designed two different Personas that are representative of the typical patients of an anticoagulant clinic.

The first persona is Emma. "She is 52 years old and works as accountant in her husband's lawyer firm. Emma knows very well how to use a computer. She feels able to learn something new when it is just explained to her. If she needs IT help, she just searches the solution online. Because of her job, she regularly uses the Internet and iPad and iPhone. Emma uses her smartphone to make phone calls, to browse the web, to play games and uses many apps that she installed personally. Emma loves to travel but unfortunately she has been diagnosed with Pulmonary Thromboembolic Disease, and because of her condition, she has to make frequent visits to her GP to measure the INR values, so her trips cannot be as long as she desires. Emma dreams about a future where she no longer has to go to the healthcare practitioner so often and where she can spend more time traveling and living a more relaxed life."

The second persona is Rupert. "He retired a year ago at the age of 64, after working for 30 years as train operator. Rupert is extremely active. He likes to go bowling once a week and loves his dancing classes. He is proud of his old car and spends an hour or two each day maintaining it in his garage. Rupert has being diagnosed with Proximal Atrial Fibrillation and since more than one year ago he has to take Warfarin to manage his condition. His family is checking on him and forced him to carry an Android smartphone with him all the time. He only knows how to make calls and send SMS but does not use applications. Rupert's vision has gotten progressively worse over the past two years and he wears glasses most of the time. He uses the computer at home and accesses the Internet to email his older daughter who lives abroad. But when he cannot read because of the text size, he just gets frustrated and gives up. He desires to decrease healthcare practitioner visits and to spend his time fixing his old car."

These two personas constitute an illustrative exercise to show what is needed for the further development of the project. We chose to present here some key issues in the range of patients to explore the implications that they may have on the design of mobile apps, but we also derived other personas for the other stakeholders involved (e.g. GPs, nurses) that we omit in this paper.

\subsection{Examination of Technical Options}

\subsubsection{Self Testing Devices}

We analysed the state of the art of the INR self-testing devices available on the market and selected the three most diffused ones, which are also the most recommended ones by Health Institutions around the world and the main information we gathered are reported in Table 1. 
Table 1 Comparison of three INR self-testing devices available on the market (updated on June 2019)

\begin{tabular}{|c|c|c|c|}
\hline INR DEVICE & $\begin{array}{lr}\text { Roche } & \text { Co- } \\
\text { aguChek } & \text { XS } \\
\text { System }^{1} & \end{array}$ & $\begin{array}{l}\text { Alere } \\
\text { INRa- } \\
\text { tio@/INRatio@2 } 2 \\
\text { PT/INR Moni- } \\
\text { toring Systems }\end{array}$ & $\begin{array}{l}\text { ITC ProTime } \\
\text { Microcoagula- } \\
\text { tion System }^{3}\end{array}$ \\
\hline PRICE & $£ 360$ & $£ 880$ & $£ 950$ \\
\hline $\begin{array}{l}\text { DETECTION } \\
\text { SYSTEM }\end{array}$ & $\begin{array}{l}\text { Amperometric } \\
\text { (electrochemical) } \\
\text { determination of } \\
\text { the PT time after } \\
\text { activation of the } \\
\text { coagulation with } \\
\text { human recombi- } \\
\text { nant thromboplas- } \\
\text { tin }\end{array}$ & $\begin{array}{l}\text { A drop of blood } \\
\text { is applied to the } \\
\text { test strip, where } \\
\text { it is drawn into } \\
\text { the test area. } \\
\text { The blood mixes } \\
\text { with reagents that } \\
\text { start the clotting } \\
\text { reaction. As the } \\
\text { blood clots, there } \\
\text { is a change in } \\
\text { the impedance in } \\
\text { the sample. The } \\
\text { monitor detects the } \\
\text { change and then } \\
\text { calculates the PT } \\
\text { for the sample and } \\
\text { reports the result } \\
\text { on the screen }\end{array}$ & $\begin{array}{l}\text { Mechanical clot } \\
\text { based technology - } \\
\text { optical detection }\end{array}$ \\
\hline $\begin{array}{l}\text { TEMPERA- } \\
\text { TURE }\end{array}$ & $18^{\circ} \mathrm{C}$ to $32^{\circ} \mathrm{C}$ & $10^{\circ} \mathrm{C}$ to $35^{\circ} \mathrm{C}$ & $15^{\circ} \mathrm{C}$ to $30^{\circ} \mathrm{C}$ \\
\hline HUMIDITY & $10 \%-85 \%$ & $15 \%-95 \%$ & - \\
\hline $\begin{array}{l}\text { HEIGHT / AT- } \\
\text { MOSPHERIC } \\
\text { PRESSURE }\end{array}$ & $\begin{array}{l}\text { Below altitudes of } \\
4300 \mathrm{~m}\end{array}$ & $\begin{array}{l}\text { Atmospheric pres- } \\
\text { sure between } 700 \\
\mathrm{hPa} \text { and } 1060 \mathrm{hPa}\end{array}$ & - \\
\hline Measuring range & $0.8-8.0$ & $0.7-7.5$ & $0.8-9.9$ \\
\hline Memory & $\begin{array}{l}100 \text { test results } \\
\text { with time and date }\end{array}$ & 120 results & 50 results \\
\hline Interface & Infrared & Cable & Cable \\
\hline Power & $\begin{array}{l}\text { Battery }-4 \times 1.5 \mathrm{v} \\
\text { AAA }\end{array}$ & $\begin{array}{l}\text { AA alkaline batter- } \\
\text { ies }\end{array}$ & $\begin{array}{l}\text { Nickel Metal } \mathrm{Hy}- \\
\text { dride }(\mathrm{NiMH})\end{array}$ \\
\hline Sample type & $\begin{array}{l}\text { Fresh capillary } \\
\text { whole blood or } \\
\text { non-anticoagulated } \\
\text { venous whole blood }\end{array}$ & $\begin{array}{l}\text { Fingerstick or ve- } \\
\text { nous }\end{array}$ & $\begin{array}{l}\text { Fingerstick or ve- } \\
\text { nous }\end{array}$ \\
\hline Sample size & $8 \mu \mathrm{L}$ & at least $15 \mu \mathrm{L}$ & $27 \mu \mathrm{L}$ \\
\hline
\end{tabular}

All these devices can be connected with PCs but their data can be collected only through proprietary applications that up to now do not allow direct access to the data for using other applications. Therefore, in the MANTRA project and especially in the design of the scenario of use and the prototypes, we considered a scenario where the patient is asked to input manually the INR value in the application without being able to directly connect the INR device to the mobile device. Of course, this does not represent the optimal solution because of the high risk of errors that can be committed by the users. However, testing the usability of a version of the application that presents such 
a challenging interaction modality assures us that in case of a further version with an automatic loading of the INR value, the process could only be easier.

MANTRA Project is focused on self-testing approach, in that the aim is not to replace the fundamental role of the healthcare practitioners in the anticoagulant therapy management, but to enable a remote communication among healthcare practitioners and patients. Several studies (e.g., [36][4][10][12][16][40]) report that the INR self-testing devices are reliable instruments and suitable alternative to conventional laboratory testing and that the INR results are typically very well reproducible and well correlated.

In addition to the above, the MANTRA Project is not focused on selfmanagement but on self-testing, because the proposed system involves actively the healthcare practitioners and is aimed at supporting the remote patienthealthcare practitioner communication. This would help the healthcare practitioners to supervise the patient health conditions avoiding the patient to be left alone during his therapy.

\subsubsection{Mobile Apps for Oral Anticoagulation Management}

INR tracking mobile applications are available both for iOS (on iTunes) and for Android (on Google Play) mobile devices. We analysed two applications for iOS, INR 8 OAT Manager ${ }^{4}$ and INR Pro ${ }^{5}$, and two for Android, INR Tracker ${ }^{6}$ and INR Tracker (Warfarin Log) ${ }^{7}$.

None of them are designed to support doctor-patient communication and are not suitable for doctors. Some applications are available for free, while others may cost up to $£ 5$. The two iOS applications allow keeping track of INR results and Warfarin prescriptions. Both give the user the possibility to see the INR results history represented on charts. The two Android applications permit to track the INR results and Warfarin prescriptions, but only INR Tracker offers the chart feature, while INR Tracker (Warfarin Log) allows to send an email with the INR result to addresses of user's choice but does not support bidirectional communication or track of emails sent.

We applied heuristic evaluation method [32] to test the usability of the four mobile applications listed above. Two usability experts were involved in the evaluations.

For the evaluations we applied the 10 Nielsen's heuristics: Visibility of system status, match between system and real world, user control and freedom, consistency and standards, error prevention, recognition rather than recall, flexibility and efficiency of use, aesthetic and minimalist design, help users recognize, diagnose, and recover from errors, help and documentation.

We adopted Nielsen's severity ranking [31] to classify the usability issues: 1) Cosmetic problem only, 2) Minor usability problem, 3) Major usability problem, 4) Usability catastrophe.

\footnotetext{
4 http://bit.1y/10ELb65

5 http://bit.ly/10ELb65

6 http://bit.ly/10Q0iGT

7 http://bit.1y/10Ju95h
} 
Heuristic evaluation is a so-called discount usability method that is especially useful in early stage of design. It is cheap and fast and does not require the participation of real end users. We evaluated the applications using these tasks: 1) The user accesses the application. 2) The user saves the INR result. 3) The user browses the INR results history. 4) The user saves the Warfarin prescription.

These four tasks represent the most important features required by an INR tracker application and are all implemented in the four mobile applications under analysis. Each of the two evaluators analysed each application twice using the two Personas described previously in this paper (Emma and Rupert).

The application with the highest number of problems (34) is INR $\& O A T$ Manager. The severity of the problems found by Rupert's persona is so high that he may not even be able to perform the basic tasks requested. In particular, the registration of INR results and prescriptions are the two most affected tasks. For the other three applications, the evaluators have found more problems with Emma's persona. Emma represents the archetypal expert user of smartphones and mobile applications. Her familiarity with mobile interaction makes her keener to find errors and deficiencies in an application. Moreover, a user like Emma does not usually limit her exploration of an application to the main tasks but happens to be more interested in interacting with the application as a whole. On the other hand, Rupert being a novice in smartphone use is more oriented to keep the use of applications at minimum, because of his fear of the unknown.

Many issues may be resolved during use in time. In these cases, learnability dimension is respected and supports the user to become more aware of the applications potentials. However, the other usability issues deeply affect other usability dimensions, like effectiveness, use satisfaction and most of all, safety.

Being the use of such applications related to health it is of great importance that safety, efficiency and effectiveness are respected. To better understand the kind of problems that affect the four mobile applications, we analysed them in respect with the 10 Nielsen principles. The four principles that appear to fail more are: Match between system and the real world, User control and freedom, Consistency and standards, and Error prevention. The problems that most seriously violate these four principles and that strongly affect effectiveness, efficiency and safety use of the applications may be classified in three main classes: Flexibility, readability, and data representation.

The applications show three serious issues in terms of flexibility that were spotted by all the evaluations, both with Emma and Rupert personas: The first issue regards the possibility of registering INR test results using a date that is different from the current one. This may represent a limitation for the patient that may be interested in registering results of tests taken in the previous days. Without this feature the patients are forced to register the INR test results with wrong dates putting at risk their own safety. A second problem is the unit used to specify the dosage of Warfarin that the doctor prescribes. One of the applications asks the patient to set a default unit measure (mgs of Warfarin contained in a tablet). After this setting operation, all the prescrip- 
tion registrations done with the application are expressed in term of units (e.g. tablets) and no more in mgs. This may represent a serious problem because of the different format of Warfarin tablets sold around the world. In the UK and several other countries, Warfarin tablets are distributed in different blister packages, each one having different mgs of Warfarin, with tablets of different colours (one colour for each Warfarin dosage).

This implies that the patients may need to take each day tablets of different kind (colour/dosage) and therefore a default unit is not suitable for them. Besides, in other European countries, Warfarin is distributed in tablets that may be cut into parts to obtain different dosages of the medicine. Also in this case, the default unit is not the correct solution for the patients. The last issue of this class of problems regards the interval of prescription: most of the applications do not allow the patients to freely specify the initial and final date of the prescription received by their GP. Typically, the applications offer the possibility to register a daily prescription (registered day by day) or a weekly prescription (from Monday to Sunday, with no possibility of personalizing this format).

As to the readability class of problem, the evaluations made with Rupert's persona pointed out the great importance of using fonts, colours (for text and background) and icons that may be easily read by patients. One important option could be to implement a feature for resizing the text size to support the accessibility especially for elderly and/or patients with sight problems. The issues related to the data representation class regard the possibility of browsing the INR test results history of the patient. It is of fundamental importance for the patients to be able to access the previous tests results to be more aware of their health conditions. To this aim, it is of great importance to offer a feature for INR test results representation in charts and lists. Some applications already offer such charts and lists, but they are not enough flexible and interactive. For example, it is not possible to specify a range of dates to use for the data visualization and the charts/lists are not interactive, i.e. the values visualized are not clickable and is not possible to see more information about the INR values and relative prescriptions. Despite the limits of the heuristic evaluation method, this preliminary analysis allowed us to understand the potentials of the use of mobile devices in this context.

\subsection{Paper Prototypes}

We developed two vertical paper prototypes: a paper prototype for patients and one for healthcare practitioners. Paperboard prototyping is a very popular approach to low-fidelity prototyping and is used especially for developing an early understanding of an interface requirements, look and feel, and layout. Paper prototypes are low-cost solutions and enable the designers to engage the domain experts and/or the end users in an early-stage evaluation of the ongoing design project. To evaluate the paper prototypes we recorded interaction videos, and we showed them to healthcare practitioners posing questions and 
collecting comments and suggestions. The feedbacks we collected were used to improve the design of the prototypes that were then translated into interactive high-fidelity prototypes as described later in the paper. It is important to state that we designed our prototypes considering to provide the patients with iPods, that are small and easy to use and bring along everyday, while we considered iPads for the general practitioners, who are more often required to visualize larger amount of data at the same time and may use the device for taking extensive notes on particular patients conditions. A few views of the paper prototypes are given in Figure 4.

\subsection{High-Fidelity Interactive Prototypes Design and Development}

Following the evaluation of the paper prototypes, we started the design and development of the two interactive high-fidelity prototypes for the MANTRA Project. With the design of the apps we tried to assess the problems detected in the study of the state of the art of existing apps for oral anticoagulation therapy monitoring, especially with what concerns readability. In fact, we provide access to previous tests results visually represented in different ways, both as lists or charts, trying to face the problems that may derive both from elderly problems in reading and from the interaction with touchscreen devices, often small.

We developed the apps for iOS 5.0+ operating system in Objective-C language using XCode IDE v4.6 and including the CorePlot plotting framework.

Views of the MANTRA app for the patients are given in Figure 5. In the top row of the picture, respectively the views of the home page, the INR results input and the results sending are shown. In the bottom row, the first view is the one that shows the INR results chart and allows the patients to access their PHR. The second view is the list of food for vitamin $\mathrm{K}$ assumption guiding and the last view is the prescription received by the healthcare practitioner.

Views of the healthcare practitioners' MANTRA app are shown in Figure 6 . In the top row of the picture, respectively the screenshots of the home page, the list of patients and one patient's record with just received INR results are shown. In the bottom row, the first view is the one that shows the INR results chart for a specific patient and allows the healthcare practitioner to access their records. The second screenshot shows the first step of a prescription creation that allows the user to choose INR period (initial and final date) and the date for the next check. The last view shows the second step of creation of the prescription where the actual dosages of Warfarin is selected by the user.

\section{Evaluation of the Sociotechnical Scenario}

The evaluation of the high-fidelity prototypes was performed at the Argyle Surgery in two distinct phases. The first was focused on studying the usability of the prototype for the GPs and other healthcare practitioners. The second 

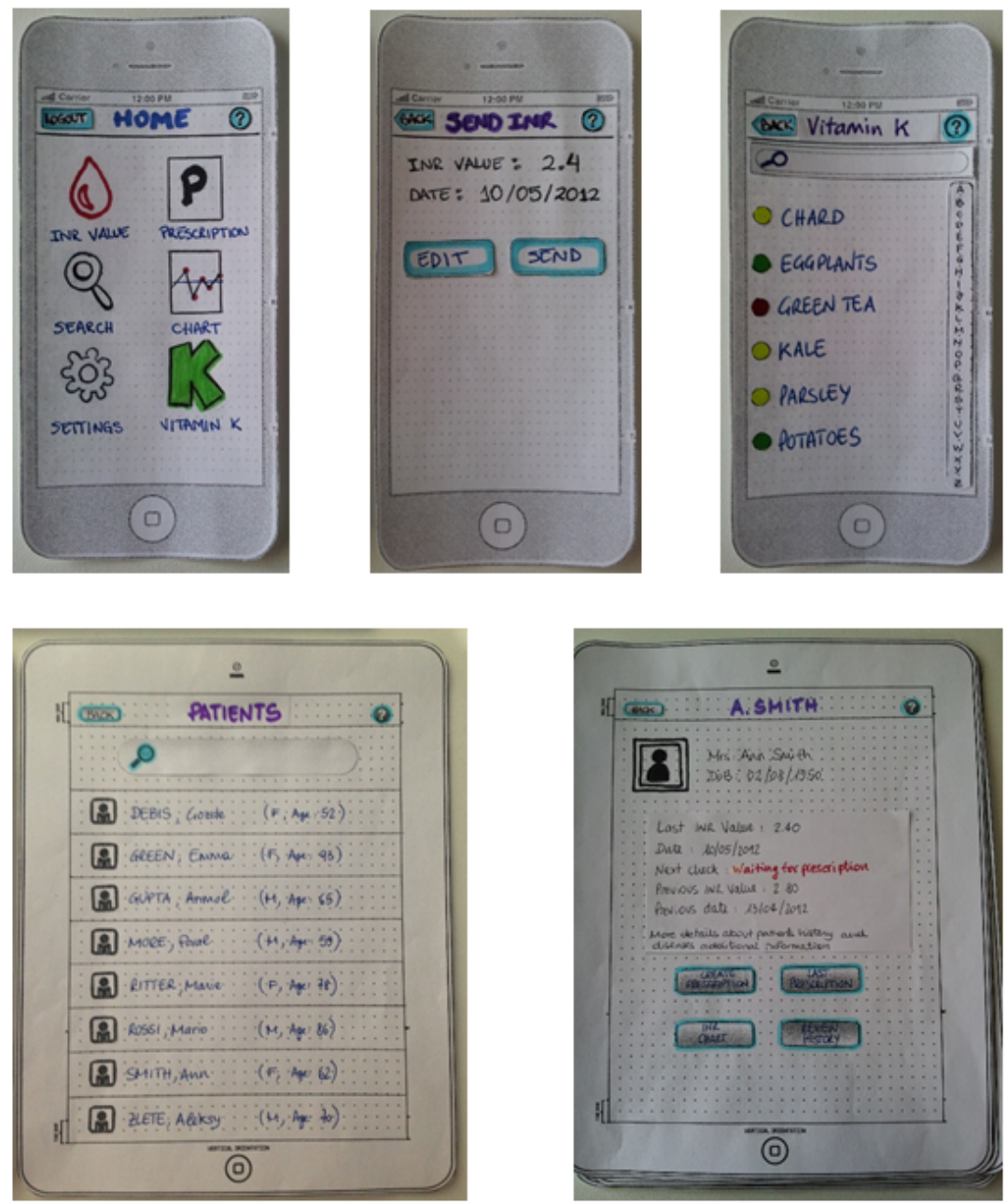

Fig. 4 In the top row, three views of the patients' app are shown, respectively: the home view, the view for sending the INR results, and the list of food for vitamin $\mathrm{K}$ assumption supervision. In the bottom row, two views of the healthcare practitioners app are show, and are: the patients list and a patient record and status information.

phase was aimed at evaluating the usability of the prototype designed for the patients by involving patients of the surgery who were on anticoagulant therapy.

6.1 Evaluation with the GPs and other Healthcare Practitioners

We were able to involve 5 healthcare practitioners in two separate occasions: a first time for individual meetings and a second one for a focus group. 

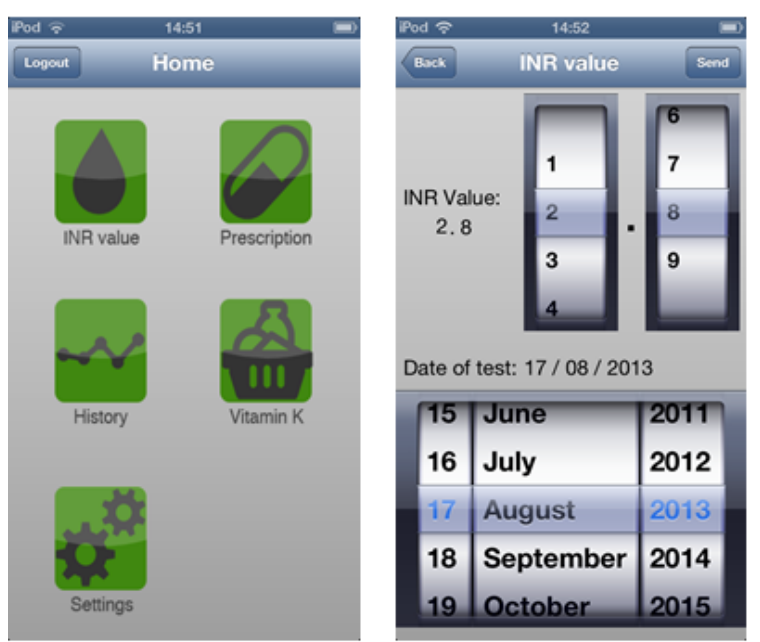

Date of test: $17 / 08 / 2013$
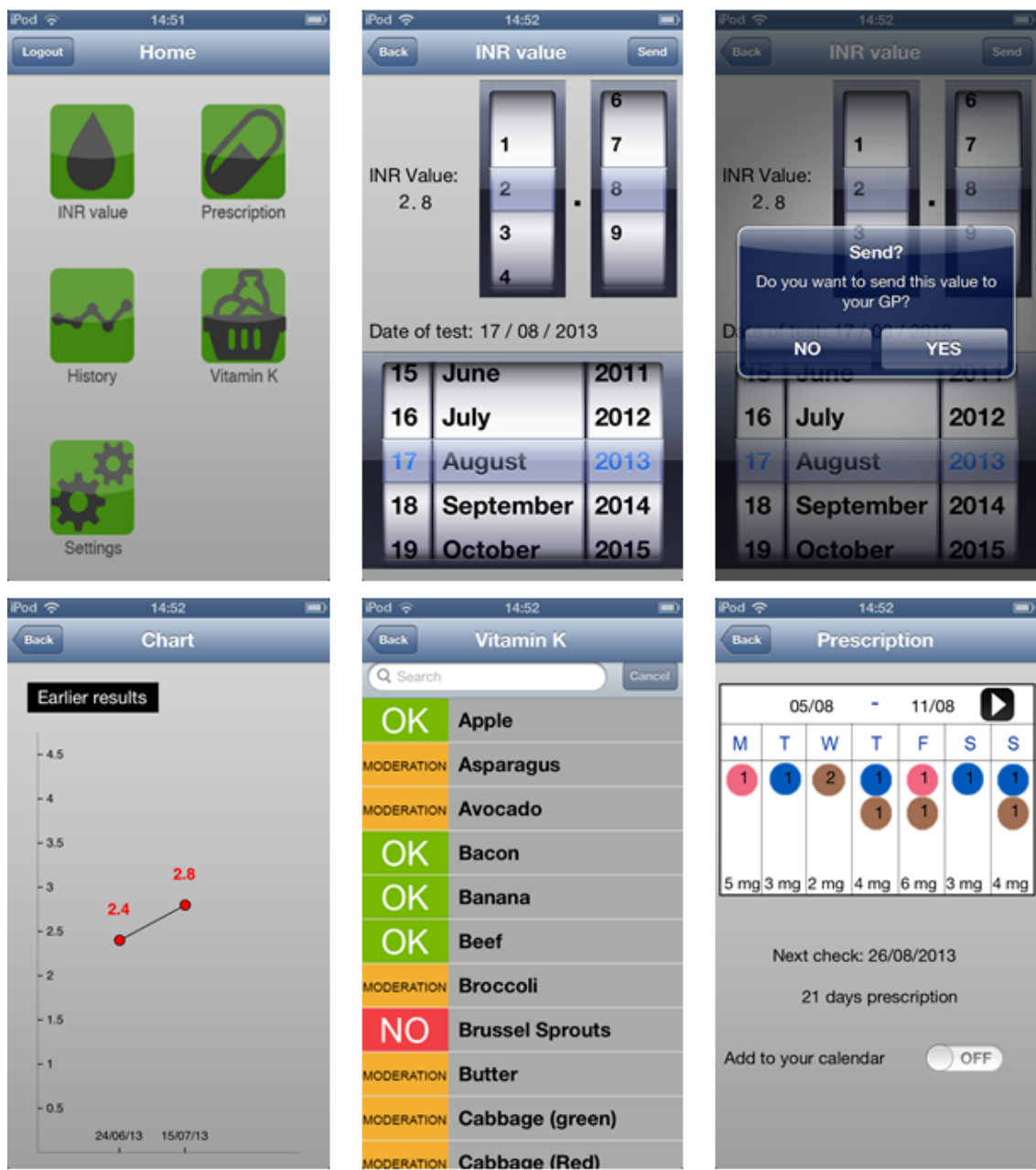

$5 \mathrm{mg} 3 \mathrm{mg} 2 \mathrm{mg} 4 \mathrm{mg} 6 \mathrm{mg} 3 \mathrm{mg} 4 \mathrm{mg}$

Next check: 26/08/2013

21 days prescription

Add to your calendar OFF

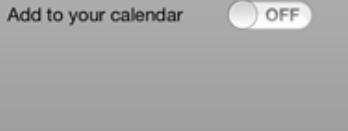

Fig. 5 Some views of the MANTRA app for the patients.

\subsubsection{Individual meetings}

During the individual meetings, we started with a semi-structured interview asking the participants about their current process in managing patients on anticoagulation therapy, the demographics of their patients receiving anticoagulation prescriptions, what factors would need to be considered in order to implement the digital solution and their views on its potential value. We also asked them about their experience in the health domain and the number of patients they manage.

We interviewed two GPs, one nurse and two Healthcare Assistants (HCAs). The nurse had 30 years' experience in the health domain, the HCAs 20 years 

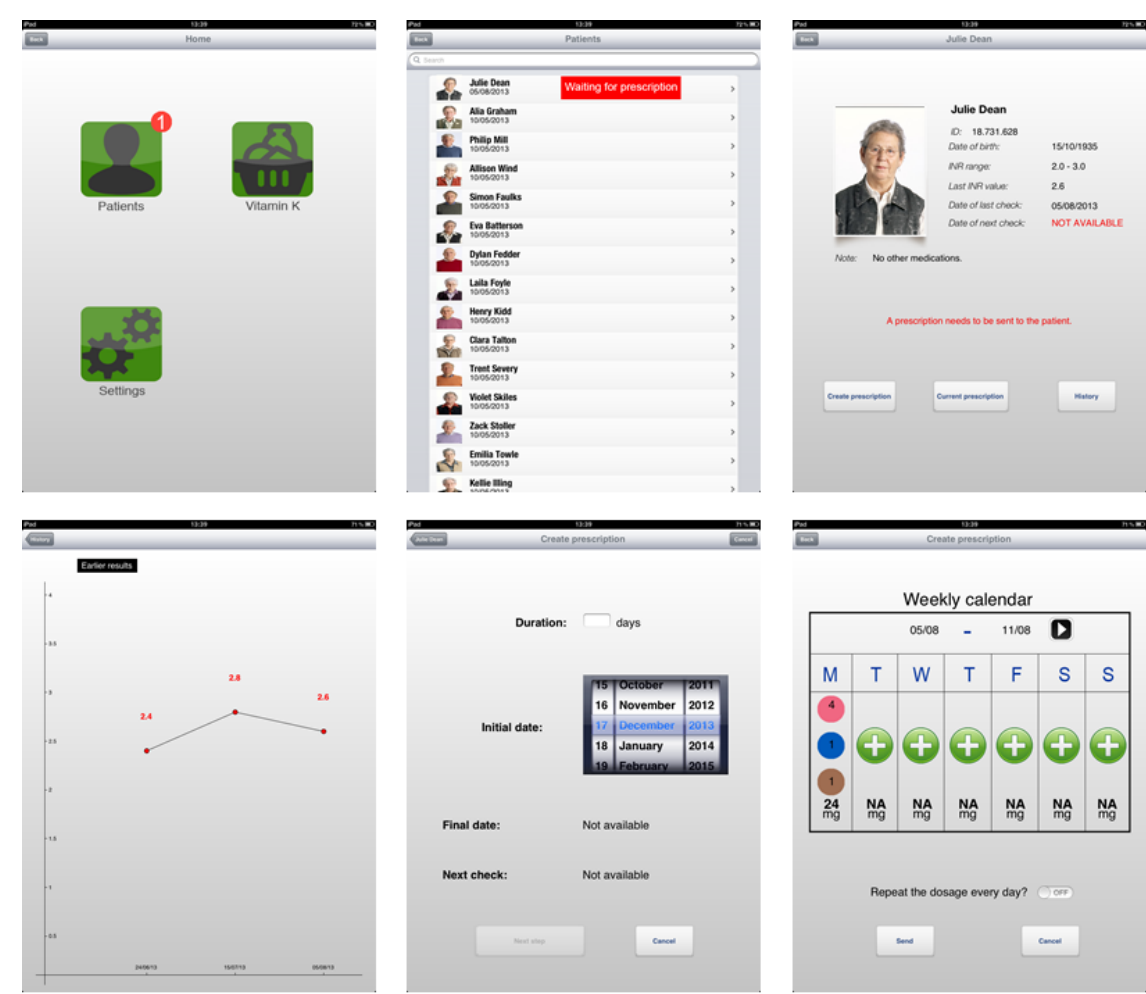

Fig. 6 Some views of the MANTRA app for the healthcare practitioners. This version is the final one, obtained after the performance of the evaluation described in the next section.

and 1 year and half, respectively, while the healthcare practitioners have 9 and 15 years of experience. The nurse and the HCAs were the ones in charge of performing the INR tests and insert the results in the INR Star system, an interactive system that automatically computes the dosage of Warfarin to be prescribed to a patient. If the INR result is too high or too low (extremely out of the range), the nurse and HCAs have to consult with a GP. The three participants managed 94 persons who were patients of the surgery, patients of other surgeries or nursing homes residents. The average age was about 60 , the youngest patient was 37 and the oldest was in his 90 s. Some of them were on a life-long anticoagulant therapy while others were only recovering from some temporary diseases.

The two GPs were the ones responsible for the management of the anticoagulant clinic, both for the patients of the surgery and for the ones of other surgeries and nursing homes. They supervised the nurse and HCAs activity and intervene in case an urgent prescription is needed.

The most important outcomes we had from the interviews regard the features that a mobile application for anticoagulant therapy should have and the sociotechnical factors to be considered in changing the current process of 
the anticoagulant clinic. As to the application's features, the most recurrent responses were: simple to use, efficient, user-friendly, simple, safe, and reliable.

The important sociotechnical factors to be considered that the participants named were: a) the application should lead to time savings given the constrained nature of resources in the NHS, b) should support healthcare practitioners mobility especially when visiting nursing homes, since to engage in this type of activity requires time and resources that are often hard to allocate and expensive, c) automatic suggestion of prescription should be avoided, because the role of the healthcare practitioner should remain central in the anticoagulant therapy, and d) patients have to feel responsible for what they are doing in order to rise awareness of risks and benefits related with anticoagulant therapy.

\subsubsection{Usability evaluations}

At the end of the interview, we involved the healthcare professionals in individual usability test during which we asked them to perform a task-based evaluation of a first version of the high-fidelity prototype we created.

The tests lasted between 20 and 30 minutes average and pointed out from 4 to 6 problems each. The participants had all previous experience in using mobile devices such tablets and smartphones and the operating systems known to them were iOS, Android, and Blackberry. They had no difficulties in using the application and performed all the tasks requested in the test. The results pointed out some usability problems to be fixed but the overall satisfaction of the use of the prototype was high.

The main problems regarded the visibility of notification icons (when a patient sends an INR test results a notification icon appears on the list of patients) that needed to be larger and the prescription creation procedure that was not completely in line with the actual practice in the UK system.

Another change that was applied passing from the first to the second version of the high-fidelity prototypes after the interviews with Argyle Surgery team, was on the Vitamin $\mathrm{K}$ section of the application: we adopted a colourcode scale for suggesting what food the patient has to avoid, limit and can freely eat. During the interviews, we were asked to pair some textual description with the colours and the result is the one presented in the pictures in the previous section of this report: we added OK, NO, and MODERATION to the colours to make the message more clear to the user.

The last change that was requested by $\mathrm{xxx}$ and was implemented in the final version of the high-fidelity prototype was to ask the patient to specify what other medication they took before taking the INR test. This would help the healthcare practitioners to understand the possible influence factors on the anticoagulation disease of the patient and in formulating a good prescription for the next period of time. 


\subsubsection{Focus group}

After the individual usability test we applied the requested changes and improvements to the prototype, and we met the participants in a final focus group during which the new final version of the application was shown and discussed. All the problems pointed out during the individual meetings were fixed and no other requests were made. The participants discussed the potentials of the introduction of the application and the new approach to anticoagulant therapy and proposed a new scenario of use that would involve the GPs at the Surgery and the nurses at the nursing homes: currently, healthcare practitioners have to personally visit nursing homes to collect INR results. In the new scenario, the nursing homes' nurses and HCAs will perform the INR tests and send via a MANTRA app the results to the surgery, where they will be evaluated by the healthcare practitioners who will then send back to the nursing homes the proper prescriptions of warfarin. The remote communication among the two sites would avoid the HCAs and nurses of the Surgery to visit personally the nursing homes to collect the INR test results and would make the process easier and faster.

\subsection{Evaluation with the Patients}

We were able to involve 6 patients at the Argyle Surgery for individual meetings (see 2). During the meetings we perform a semi-structured interview with each them, and we also involved them in a usability test of the MANTRA application. For the usability test the final version of the high-fidelity prototype was used.

All the patients had to take the INR test every $2 / 3$ weeks or 1 month. 4 out of six patients were retired while the other two still worked, but they both did not have any problems in visiting the Surgery because they lived and worked in the neighborhood. All the patients would positively consider the possibility of having an INR self-testing device at home and to communicate with the healthcare practitioners on a distance because they felt it would be easier and faster. Even if some of the patients had only a little or no experience at all in using smartphones and touchscreen interaction, they seemed to have no difficulties at all in interacting with the application and successfully performed all the tasks in the list. The three patients who never used a touchscreen before received an initial explanation about how to tap on a graphic element on the interface, how to scroll a page and how to use the wheel widget.

The patients did not suggest specific changes to the application and demonstrate to understand the entire process of sending the INR test result and receiving the prescription from the healthcare practitioner. One of the two patients strongly appreciated the Vitamin K list because he said he was used to reading one that was printed on paper but the digital one was easier to be used. Two of the patients did not find useful the Alarm feature and said that they are used to taking their medicine every day at the same time without 
Table 2 Characteristics of the patients involved in the evaluation of the MANTRA Project

\begin{tabular}{|c|c|c|c|c|}
\hline AGE & $\begin{array}{l}\text { THERAPY } \\
\text { SINCE }\end{array}$ & DISEASE & $\begin{array}{l}\text { MOBILE } \\
\text { PHONE }\end{array}$ & $\begin{array}{l}\text { USE OF } \\
\text { SMART- } \\
\text { PHONE }\end{array}$ \\
\hline 75 & 4 years & $\mathrm{AF}$ & $\begin{array}{lr}\text { Yes, } & \text { touch- } \\
\text { screen } & \text { (An- } \\
\text { droid) } & \end{array}$ & $\begin{array}{l}\text { Phone calls, } \\
\text { calendar, no } \\
\text { apps, no inter- } \\
\text { net browsing, } \\
\text { no games }\end{array}$ \\
\hline 63 & 1 year & $\mathrm{AF}$ & $\begin{array}{lr}\text { Yes, } & \text { touch- } \\
\text { screen } & \text { (An- } \\
\text { droid) } & \end{array}$ & $\begin{array}{l}\text { Phone calls, } \\
\text { calendar, no } \\
\text { apps, no inter- } \\
\text { net browsing, } \\
\text { no games }\end{array}$ \\
\hline 73 & $>10$ years & $\mathrm{AF}$ & No & - \\
\hline 72 & 10 years & Stroke & $\begin{array}{l}\text { Yes, not touch- } \\
\text { screen }\end{array}$ & - \\
\hline 68 & $>12$ years & DVT & No & - \\
\hline 41 & 6 months & $\begin{array}{l}\text { Kidney trans- } \\
\text { plant }\end{array}$ & $\begin{array}{l}\text { Yes, touch- } \\
\text { screen } \\
\text { (iPhone) }\end{array}$ & $\begin{array}{l}\text { Phone calls, } \\
\text { apps, inter- } \\
\text { net browsing, } \\
\text { games }\end{array}$ \\
\hline
\end{tabular}

needing an alarm however, they liked to have the chance to see the prescription details on the phone. All the patients also described the application as useful and easy to use.

\subsection{Limitations of the Study}

The present research has some limitations, especially related to the number of participants involved in the study, even if all the involved patients and healthcare professionals were expert of the problem at hand and of the challenges and open problems to be addressed. To overcome these limitations, a further study with more patients and domain experts should be developed and eventually the personas created for this study would be updated accordingly to the new outcomes.

\section{Discussion and Conclusion}

To understand what has the proof of concept study of the MANTRA project found we can start reflecting on the effects of technology on the conversation between patient and GP. This peculiar aspect of the synchronous co-located interaction between the two actors may often lead to a loss of empathy in the way the GP addresses the patient's needs. This emerges clearly from the literature review and the interviews with the domain experts. The need of learning new ways of communication (asynchronous remote interaction, that are mainly related to the risk of patients and providers being afraid of learning 
new ways of communicating with each other and help them understanding the potentials of this specific setting.)

The changes in the traditional roles of patients and healthcare providers (i.e., the changes in the traditional roles of patients and healthcare providers with the introduction of more and more pervasive and ubiquitous technologies) and the proactivity of patients in sending their own test results to the GPs may lead to great advantages in a long term perspective, but it is undoubtedly hard to be understood and acknowledged in the short term.

With reference to the literature on eHealth, MANTRA outcomes positively respond to the critical issues described in Section 3. Specifically, as to the five potential changes, highlighted in [11], that can be caused by the introduction of remote and mobile health:

1. "Internet health Websites may become a replacement for face-to-face consultations influencing deeply the patients understanding of their health conditions and putting at risk their own safety and future." The MANTRA approach is aimed at establishing a remote form of communication between patient and healthcare practitioners and not on the replacement of the consultations with an automatic system for self-management. In fact, in our study we developed and tested systems for the self-testing of INR and not for self-management of anticoagulant therapy. This was positively evaluated by the healtcare practitioners involved in the individual meetings, usability testing and focus group and also by the patients involved in the user tests.

2. "Supplement existing relationships and forms of care, that means making the computer-mediated conversation between patient and GP an actual bi-directional transaction but always allowing the receiver (the GP) driving the communication." The relationship between patient and healthcare practitioners remains bi-directional. During the focus group, one GP expressed a great interest in the integration of a new feature in the system: the possibility of sending the patient some messages asking her/him to visit the clinic for further examination.

3. "Create favorable circumstances for improvements or for strengthening patient participation, by mitigating mechanism, offering a training ground, and implementing a so-called lever effect". Both patients and healthcare practitioners expressed their interest in using the MANTRA approach for improving the quality of life of the people under anticoagulant medications. Patient participation is one of the main and direct consequences of the application of such approach and as a HCA suggested, especially the younger patients would probably be interested in changing their current therapy management situation.

4. "Managing the issues that the healthcare practitioners might encounter, like the feeling of power loss, the fear of damaging the relationship with the patients during a remote conversation, and to lose control over the sources of information that tend to proliferate very fast due to technological advances." We developed usable prototypes that demonstrated to patients 
and healthcare practitioners that the management of remote communication of anticoagulant prescriptions can be easy and secure. The possibility of checking on the history of patients gives the GPs and HCAs a control over information and the use of mobile devices makes them feel free to manage the clinic in a more flexible way.

5. "Forcing the patient to become a more capable conversation partner because $\mathrm{s} /$ he needs to provide the doctor with information that the doctor cannot obtain through remote conversation." Despite the simplicity of the prototypes, they allow the healthcare practitioners to collect all the information they need for submitting a prescription.

From the results of this study, we were able to address the sociotechnical challenges we identified and classified into four main classes: quality of life, prescription management, treatment schedule, and nutrition.

In particular, with our research and design we addressed the main open problems/challenges we described in Section 3.3:

1. Problems in the management of INR test schedule. In particular, the test have to be done in certified facilities that could be far away from patients home and that in any case imply time and resources allocation. With MANTRA the patients are allowed to perform the INR tests independently and to send the results to the clinic for receiving the right prescription in a remote way. This approach gives the patient more freedom and less constrained by test schedules.

2. The communication of INR test results and of the related dosage is done in different ways that often may not be accessible for children and elderly and very time/resources consuming for pupils and working adults. Our approach allows to manage a remote communication protocol that helps not only the patients but also their families and/or caregivers in managing the anticoaugulant therapy remotely and in a easier way.

3. Difficulties in the management of the daily dosage of oral anticoagulants. Patients have to keep a diary and to remember which dosage they have to take in specific days of the week. Errors in this particular task may be fatal. The use of mobile devices in the MANTRA approach helps the patients in remembering their pills thanks to alarms and calendar features.

4. Nutrition rules should be followed by the patient and very often they represent a limit to their social life. In fact, in case of doubts the patients do not know how to decide if a certain food can be assumed or not and if such food would affect the INR value.

5. The limitations given by coagulation diseases cause problems in social and personal life, and may lead the patients to feel uncomfortable with their daily life and sometimes isolated from the community.

The methodology and approach we applied in MANTRA Project can be easily be adapted for other chronic diseases remote management cases. In particular, four sociotechnical factors can be derived from this experience and applied to different therapy management contexts in public-funded health institutes: 
1. Flexibility: drugs prescription modalities is strictly linked to regulations of the local National health systems. Internationalization of software allows to adapt the interface to the user's Country of residence, enabling the designer and developers to create application that can be used in different places but sharing the same aim.

2. Accessibility: most of the patients who follow an anticoagulant therapy are elderly. Since with age come very often sight problems it is highly important to design accessible interfaces that cannot lead the user in making mistakes. This applies both to software and to hardware: choosing the right device and interaction techniques enhances the chances of success of the introduction of digital solutions in chronic diseases remote management.

3. Data visualization: it is fundamental for the user to access history of therapy to learn from previous behavior and to monitor improvement or retrogression. To show a large amount of data in an effective and efficient way calls for an accurate design of interface and interaction style.

4. Safety: together with efficiency and effectiveness, safeness is one of the most important characteristics that a mHealth application should have to be considered as appropriate for a clinical use.

As a future development, we plan to expand the study to other Countries and to focus on the development of the final mobile applications by improving the high-fidelity prototypes using the results we obtained from the usability evaluations. We also would like to explore different application of the MANTRA approach also following what suggested by the Argyle Surgery's healthcare practitioners about using mobile devices to remotely managing nursing homes.

\section{Ethical statement}

The authors whose names are listed above certify that all procedures performed in studies involving human participants were in accordance with the ethical standards of the institutional and/or national research committee and with the 1964 Helsinki declaration and its later amendments or comparable ethical standards. The Project went under Ethical approval through the NHS and University of West London in 2013.

\section{Acknowledgements}

Acknowledgements The MANTRA Project was funded by the Leverhulme Trust with a Visiting Fellowship for Barbara Rita Barricelli at the University of West London.

\section{References}

1. Abdelnour-Nocera, J.: The Social Construct of Usefulness: An intercultural study of producers and users of a business information system. VDM Verlag (2007) 
2. Barricelli, B., Devis, Y.: Mhealth in resource-constrained environments. International Journal of Sociotechnology and Knowledge Development 6(1), 18-35 (2014). DOI 10.4018/ijskd.2014010102

3. Barricelli, B.R., Devis, Y., Abdelnour-Nocera, J., Wilson, J., Moore, J.: Mantra: Mobile anticoagulant therapy management. In: 2013 7th International Conference on Pervasive Computing Technologies for Healthcare and Workshops, pp. 278-281. IEEE (2013). DOI 10.4108/icst.pervasivehealth.2013.252096

4. Bussey, H.I., Chiquette, E., M., B.T., Lowder-Bender, K., Kraynak, M.A., Linn, W.D., Farnett, L., Clark, G.M.: A statistical and clinical evaluation of fingerstick and routine laboratory prothrombin time measurements. Pharmacotherapy 17(5), 861-866 (1997). DOI 10.1002/j.1875-9114.1997.tb03775.x

5. Callon, M.: Mapping the Dynamics of Science and Technology: Sociology of Science in the Real World. Sheridan House (1986)

6. Camara, S., Abdelnour-Nocera, J.: Revealing the socio-technical context of design settings: Toward participatory is design. International Journal of Human-Computer Interaction 29(4), 289-307 (2013). DOI 10.1080/10447318.2013.765767

7. Chen, Q.L., Dong, L., Dong, Y.J., Zhao, S.L., Fu, B., Wang, Y.Q., Jiang, H.: Security and cost comparison of inr self-testing and conventional hospital inr testing in patients with mechanical heart valve replacement. Journal of Cardiothoracic Surgery 10(1) (2015). DOI 10.1186/s13019-015-0205-1. URL https://www.scopus. com/inward/record.uri?eid=2-s2.0-84928669219\&doi=10. 1186\%2f s 13019-015-0205-1\&partner ID=40\&md5=311e38829a90a399bca08955e6ee 1250

8. Chen, Y., Cheng, K., Tang, C., Siek, K.A., Bardram, J.E.: Is my doctor listening to me?: Impact of health it systems on patient-provider interaction. In: CHI '13 Extended Abstracts on Human Factors in Computing Systems, CHI EA '13, pp. 2419-2426. ACM (2013). DOI 10.1145/2468356.2468791

9. Christensen, H., Lauterlein, J., Sørensen, P., Petersen, E., Madsen, J., Brandslund, I.: Home management of oral anticoagulation via telemedicine versus conventional hospitalbased treatment. Telemedicine and eHealth 17(3), 169-176 (2011). DOI 10.1089/tmj.2010.0128

10. Cromheecke, M.E., Levi, M., Colly, L.P., de Mol, B.J.M., Prins, M.H., Hutten, B.A., Mak, R., Keyzers, K.C.J., Büller, H.R.: Oral anticoagulation self-management and management by a specialist anticoagulation clinic: a randomised cross-over comparison. The Lancet 356(9224), 97-102 (2000). DOI http://dx.doi.org/10.1016/S0140-6736(00) 02470-3

11. Dedding, C., van Doorn, R., Winkler, L., Reis, R.: How will e-health affect patient participation in the clinic? a review of e-health studies and the current evidence for changes in the relationship between medical professionals and patients. Social Science \& Medicine 72, 49-53 (2011). DOI 10.1016/j.socscimed.2010.10.017

12. Dorfman, D.M., Goonan, E.M., Boutilier, M.K., Jarolim, P., Tanasijevica, M., Goldhaber, S.Z.: Pointofcare (poc) versus central laboratory instrumentation for monitoring oral anticoagulation. Vascular Medicine 10(1), 232-237 (2005). DOI 10.1191/ $1358863 x 05$ vm587oa

13. Duncan, A.S., Beabes, M.A.: Contextual inquiry: grounding your design in user's work. Conference companion on Human factors in computing systems. ACM Press (1995)

14. Eason, K., Waterson, P., Davda, P.: The sociotechnical challenge of integrating telehealth and telecare into health and social care for the elderly)., pp. 1177-1189. IGI Global (2015)

15. Ehn, P.: Work-Oriented Design of Computer Artifacts. L. Erlbaum Associates Inc. (1990)

16. Gardiner, C., Williams, K., Mackie, I.J., Machin, S.J., Cohen, H.: Patient selftesting is a reliable and acceptable alternative to laboratory inr monitoring. $\mathrm{Br} \mathrm{J}$ Haematol 128(2), 242-247 (2005). DOI 10.1111/j.1365-2141.2004.05300.x

17. Gardiner, C., Williams, K., Mackie, I.J., Machin, S.J., Cohen, H.: Can oral anticoagulation be managed using telemedicine and patient self-testing? a pilot study. Clinical \& Laboratory Haematology 28(2), 122-125 (2006). DOI 10.1111/j.1365-2257.2006.00759.x

18. Gerdes, M., Martinez, S., Smaradottir, B., Fensli, R., Jortveit, J.: Warfarin guide: Co-design of a mobile computer-assisted anticoagulant therapy. 
Studies in Health Technology and Informatics 245, 1222 (2017). DOI 10.3233/978-1-61499-830-3-1222. URL https://www.scopus.com/inward/record. uri?eid=2-s2.0-85040511672\&doi=10.3233\%2f 978-1-61499-830-3-1222\&partnerID= 40\&md5=9dd1b2453bc37819bf af 2502e5a229c4

19. Hamine, S., Gerth-Guyette, E., Faulx, D., Green, B.B., Ginsburg, S.A.: Impact of mhealth chronic disease management on treatment adherence and patient outcomes: A systematic review. J Med Internet Res 17(2), e52 (2015). DOI 10.2196/jmir.3951

20. Hansen, T.R.: Strings of experiments: looking at the design process as a set of sociotechnical experiments. In: Proc. PDC 2006, pp. 1-10. ACM (2006)

21. Hasenkam, J., Kimose, H.H., Knudsen, L., Grønnesby, H., Halborg, J., Christensen, T., Attermann, J., Pilegaard, H.: Self management of oral anticoagulant therapy after heart valve replacement. European Journal of Cardio-Thoracic Surgery 11(5), 935-42 (1997). DOI 10.1016/S1010-7940(97)01204-9

22. Heneghan, C., Ward, A., Perera, R.: Self-monitoring of oral anticoagulation: Systematic review and meta-analysis of individual patient data. The Lancet 379(9813), 322-334 (2012). DOI 10.1016/S0140-6736(11)61294-4. URL https://www.scopus.com/inward/ record.uri?eid=2-s2.0-84856387132\&doi=10.1016\%2f S0140-6736\% $2811 \% 2961294-4 \&$ partner ID $=40 \&$ md $5=d d 5085 \mathrm{ca} 2 \mathrm{~d} 4 \mathrm{e} 29219361 \mathrm{fb} 81 \mathrm{ae} 1 \mathrm{af} 9 \mathrm{f} 5$

23. Javitt, J.C., Shane Reese, C., Derrick, M.K.: Deployment of an mhealth patient monitoring solution for diabetes - improved glucose monitoring leads to reduction in medical expenditure. US Endocrinology 9(2), 119-123 (2013). DOI 10.17925/USE.2013.09.02.119

24. Kleimann, S.: Response to "using contextual inquiry". SIGDOC Asterisk J. Comput. Doc. 20(1), 22-24 (1996). DOI 10.1145/227614.228150

25. Latour, B.: We Have Never Been Modern. Harvard University Press (1993)

26. Law, J., Hassard, J.: Actor Network Theory and After. Blackwell (1999)

27. Lin, A., Silva, L.: The social and political construction of technological frames. Eur. J. Inf. Syst. 14, 49-59 (2005)

28. Miaskiewicz, T., Kozar, K.: Personas and user-centered design: How can personas benefit product design processes? Design Studies (32), 417-430 (2011). DOI 10.1016/j.destud. 2011.03.003

29. Nagler, M., Bachmann, L., Schmid, P., Raddatz Müller, P., Wuillemin, W.: Patient self-management of oral anticoagulation with vitamin $\mathrm{k}$ antagonists in everyday practice: Efficacy and safety in a nationwide long-term prospective cohort study. PLoS ONE 9(4) (2014). DOI 10.1371/journal.pone.0095761. URL https: //www. scopus.com/inward/record.uri?eid=2-s2.0-84899686376\&doi=10.1371\% $2 \mathrm{f}$ journal . pone $.0095761 \&$ partner $I D=40 \& m d 5=4397 \mathrm{a} 1$ ea $04858664 \mathrm{f} 836 \mathrm{a} 3 \mathrm{cb} 7 \mathrm{a} 2 \mathrm{f} \mathrm{c} 9 \mathrm{a} 9$

30. NHS: National patient safety agency (npsa nhs) guide to setting up an anticoagulation clinic in primary care. Tech. rep., NHS (2016). URL http://www.slcsn.nhs.uk/af/ af-anticoagulation.html

31. Nielsen, J., Mack, R.: Usability inspection methods. Wiley (1994)

32. Nielsen, J., Molich, R.: Heuristic evaluation of user interfaces. In: Proc. ACM CHI 1990 Conf., pp. 249-256 (1990)

33. Pozzi, M., Mitchell, J., Henaine, A., Hanna, N., Safi, O., Henaine, R.: International normalized ratio self-testing and self-management: Improving patient outcomes. Vascular Health and Risk Management 12, 387-392 (2016). DOI 10.2147/VHRM.S85031. URL https://www.scopus.com/inward/record.uri?eid=2-s2.0-84994453150\&doi= 10.2147\%2f VHRM. S85031\&partner ID $=40 \& \mathrm{md} 5=\mathrm{c} 00005415578 \mathrm{e} 85451018 \mathrm{f}$ ac 5 ec 24382

34. Pruitt, J., Grudin, J.: Personas: practice and theory. In: Proceedings of the 2003 conference on Designing for user experiences (DUX '03), pp. 1-15 (2003)

35. Salvador, C.H., Ruiz-Sanchez, A., de Mingo, M.A.G., Carmona Rodriguez, M., Carrasco, M.P., Sagredo, P.G., Fragua, J.A., Caballero-Martinez, F., Garcia-Lopez, F., MarquezMontes, J., Monteagudo, J.L.: Evaluation of a telemedicine-based service for the followup and monitoring of patients treated with oral anticoagulant therapy. Trans. Info. Tech. Biomed. 12(6), 696-706 (2008). DOI 10.1109/TITB.2008.910750

36. Schneeweiss, S., Gagne, J.J., Patrick, A.R., Choudhry, N.K., Avorn, J.: Comparative efficacy and safety of new oral anticoagulants in patients with atrial fibrillation. Circulation: Cardiovascular Quality and Outcomes 5, 480-486 (2012). DOI 10.1161/CIRCOUTCOMES.112.965988 
37. Smaradottir, B., Martinez, S., Borycki, E., Loudon, G., Kushniruk, A., Jortveit, J., Fensli, R.: User evaluation of a smartphone application for anticoagulation therapy. Studies in Health Technology and Informatics 247, 466-470 (2018). DOI 10.3233/978-1-61499-852-5-466. URL https://www.scopus.com/inward/record.uri? eid=2-s2.0-85046543757\&doi=10.3233\%2f978-1-61499-852-5-466\&partner ID=40\& $\mathrm{md5}=\mathrm{ba} 61 \mathrm{a} 26 \mathrm{bb} 8 \mathrm{f}$ ea33f $754473719 \mathrm{~b} 50 \mathrm{c} 696$

38. Thompson, J., Burkhart, H., Daly, R., Dearani, J., Joyce, L., Suri, R., Schaff, H.: Anticoagulation early after mechanical valve replacement: Improved management with patient self-testing. Journal of Thoracic and Cardiovascular Surgery 146(3), 599-604 (2013). DOI 10.1016/j.jtcvs.2012.03.088. URL https: //www. scopus. com/inward/record.uri?eid=2-s2.0-84881616330\&doi=10.1016\%2f j. jtcvs . 2012.03.088\&partner ID $=40 \& \mathrm{md5}=\mathrm{d} 497 \mathrm{ed} 8655 \mathrm{f}$ ad35a24d1d01a60c8d8a9

39. Thompson, J., Sundt, T., Sarano, M., Santrach, P., Schaff, H.: In-patient international normalized ratio self-testing instruction after mechanical heart valve implantation. Annals of Thoracic Surgery 85(6), 2046-2050 (2008). DOI 10.1016/j.athoracsur.2008.01.051. URL https://www.scopus.com/inward/record.uri? eid=2-s2.0-43649089685\&doi=10.1016\%2f $j$. athoracsur. 2008.01.051\&partner ID=40\& $\mathrm{md} 5=8231 \mathrm{f} 06 \mathrm{~d} 6 \mathrm{dc} 20 \mathrm{a} 69 \mathrm{c} 0505 \mathrm{c} 828375 \mathrm{e} 54 \mathrm{a}$

40. Tripodi, A.: Prothrombin time international normalized ratio monitoring by selftesting. Curr Opin Hematol 11(3), 141-145 (2004) 